\title{
(2) OPEN ACCESS \\ Improving function in people with hip-related pain: a systematic review and meta-analysis of physiotherapist-led interventions for hip-related pain
}

- Additional material is published online only. To view, please visit the journal online (http://dx.doi.org/10.1136/ bjsports-2019-101690).

${ }^{1}$ Latrobe Sports Exercise Medicine Research Centre School of Allied Health, Human Services and Sport, La Trobe University, Bundoora, Victoria, Australia

${ }^{2}$ Faculty of Health Sciences, Western University, London, Ontario, Canada ${ }^{3}$ Schulthess Clinic Human Performance Lab, Zurich, Switzerland

${ }^{4}$ La Trobe University Library, La Trobe University, Melbourne, Victoria, Australia

${ }^{5}$ Department of Physiotherapy, Podiatry and Prosthetics and Orthotics, La Trobe University, Melbourne, Victoria, Australia

\section{Correspondence to} Dr Joanne L Kemp, Latrobe Sports Exercise Medicine Research Centre, School of Allied Health, Human Services and Sport, La Trobe University, Bundoora, VIC 3086, Australia; j.kemp@latrobe.edu.au

Accepted 19 April 2020 Published Online First 6 May 2020

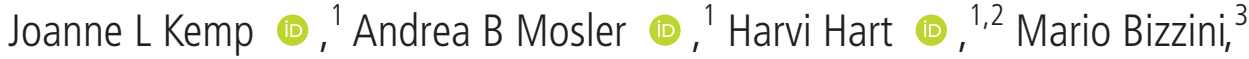 \\ Steven Chang 이, ${ }^{4}$ Mark J Scholes 다, ${ }^{1}$ Adam I Semciw 다, ${ }^{1,5}$ Kay M Crossley
}

\section{ABSTRACT}

Objective To report the effectiveness of physiotherapist-led interventions in improving pain and function in young and middle-aged adults with hiprelated pain.

Design Systematic review and meta-analysis.

Data sources A comprehensive, reproducible search strategy was performed on five databases in May 2019. Reference lists and grey literature were also searched. Eligibility criteria for selecting studies Population: people aged $\geq 18$ years with hip-related pain (with or without a diagnosis of femoroacetabular impingement syndrome). Intervention(s): physiotherapist-led interventions for hip pain. Comparators: sham treatment, no treatment or other treatment (eg, hip arthroscopic surgery). Outcomes: primary outcomes included patientreported hip pain and function. Secondary outcomes included physical function measures.

Results 1722 papers were identified. After exclusion criteria were applied, 14 studies were included for analysis. They had varied risk of bias. There were no full-scale placebo-controlled randomised controlled trials (RCTs) of physiotherapist-led treatment. Pooled effects ranged from moderate effects $(0.67(95 \% \mathrm{Cl} 0.07$ to 1.26)) favouring physiotherapist-led intervention over no treatment post-arthroscopy, to weak effects $(-0.32$ (95\% Cl 0.57 to 0.07)) favouring hip arthroscopy over physiotherapist-led treatment.

Conclusion Physiotherapist-led interventions might improve pain and function in young and middle-aged adults with hip-related pain, however full-scale highquality RCT studies are required.

PROSPERO registration number CRD42018089088.

\section{BACKGROUND}

Musculoskeletal conditions, such as hip-related pain, are leading causes of pain and disability in the community, and the second largest global contributor to years lived with disability. ${ }^{1}$ Hip and groin injuries are common in active individuals, for example, accounting for up to $18 \%$ of professional male football injuries. ${ }^{2-4}$ The true prevalence of non-arthritic hip pain in the general population is unknown, however the burden of hip pain is high, with younger adults with hip-related pain reporting poor patient-reported outcome scores for pain, physical activity and quality of life $^{5-8}$ at a time of life where work and family commitments are large.

Hip-related pain may be classified into three categories, including femoroacetabular impingement (FAI) syndrome, acetabular dysplasia and other pathology without morphological variants (labral, chondral and ligamentum teres pathology). ${ }^{9}$ Of these, FAI syndrome is the most commonly diagnosed clinical condition ${ }^{10}$ and is evident in $49 \%$ of people with hip pain. ${ }^{11}$ Patients with FAI syndrome present with pain, a morphological variant in hip shape on radiographs, with or without intraarticular imaging findings such as labral and/or chondral pathology, ${ }^{12}$ and reduced activity and quality of life. ${ }^{13} 14$

Non-surgical treatment approaches should be the first-line options for musculoskeletal pain conditions (evident from clinical guidelines for osteoarthritis $(\mathrm{OA})^{15} 16$ and low back pain, ${ }^{17}$ due to the far greater costs and risks associated with surgery. Establishing the efficacy of non-surgical treatments for hip pain is critical. Physiotherapist-led interventions have the potential to reduce the burden of hip pain, with current evidence guiding physiotherapist-led treatments to target characteristic modifiable physical impairments ${ }^{18}$ (strength, range of motion, functional task performance, neuromuscular/motor/movement control). At present, the level of evidence supporting the efficacy of physiotherapist-led interventions for hip pain and FAI syndrome is unclear.

\section{Review aim}

This systematic review aimed to identify the effectiveness of physiotherapist-led interventions in improving pain and function in young and middle-aged adults who experience hip pain, when compared with sham treatment, no treatment and other treatment. This included non-operative and postoperative patient groups. This review specifically used the participants, interventions, comparators, outcomes (PICO) format.

\section{METHODS}

This systematic review was conducted according to the Preferred Reporting Items for Systematic Reviews and Meta-Analyses guidelines. Literature search criteria and methods were proposed and agreed on by two authors (JK, SC), and were established a priori to minimise selection bias.

\section{Eligibility criteria for selecting studies}

Studies were eligible for inclusion if they were reported in English; reported level IV evidence or above; contained human subjects with hip pain; had at least 10 participants in the overall study sample (5 per group in studies with more than one group) 
and examined the effectiveness of physiotherapist-led interventions. All quantitative study designs were considered, including randomised controlled trials (RCTs), prospective or retrospective approaches. ${ }^{19}$ Studies were excluded if: hip pain was due to hip OA, dysplasia or congenital disorder; greater trochanteric pain syndrome and other conditions that are not related to the hip joint; the study evaluated other therapies that were not physiotherapist-led interventions; the study included populations of children or older adults (aged $>50$ years) or the study was a published abstract, non-peer-reviewed or was written in a language other than English.

\section{Participants/Population}

People aged $18-50$ years with hip pain (based on the mean or median age of the study sample), including studies that included a diagnosis of FAI syndrome.

\section{Intervention(s), exposure(s)}

Studies reporting physiotherapist-led interventions for hip pain and/or function were included.

\section{Comparator(s)/Control}

Studies using sham treatment, no treatment or other treatment (eg, hip arthroscopy surgery) as the comparator/control treatment were included.

\section{Outcomes}

Primary outcomes included patient-reported hip pain and function. Secondary outcomes included: hip joint range of motion, hip muscle strength, functional task performance, electromyography (EMG) and motor control, balance and proprioception, biomechanics and gait analysis and other patient-reported outcome measures.

\section{Search strategy}

A comprehensive, reproducible search strategy was performed on the following databases from earliest available to 6 November 2017 and was then repeated on 20 May 2019: Medline, CINAHL, Cochrane library, EMBASE and PEDro. Reference lists of included studies were also manually searched for relevant papers. Grey literature, including the Clinical Trials database and the Australia and New Zealand Clinical Trials Registry were searched to identify potential studies that may have been published. Where data were insufficient, authors were contacted and asked to provide missing data. The search terms used PICO format and full search strategy of each database is contained in online supplementary appendix 1 . The search strategy was conducted by two reviewers (JK, SC) and used the PICO format, and included:

- $\mathbf{P}=$ human adults (18-50 years) with hip pain.

- $\mathrm{I}=$ physiotherapist-led interventions.

- $\mathrm{C}=$ sham treatment, no treatment, other treatment (eg, surgery).

- $\mathrm{O}=$ pain, function, other patient-reported outcome measures. Function may include hip joint range of motion, hip muscle strength, measures of functional task performance, EMG, gait analysis.

We also used Web of Science to track the forward and backward citations and reference lists of included studies. The strategy was adapted as appropriate for each database. The full search strategy used is contained in online supplementary appendix 1 .

Title, abstract and full-text screening was conducted by two independent reviewers $(\mathrm{JK}, \mathrm{HH})$ using Covidence (Veritas
Health Innovation, Australia) software. Any disagreements were resolved by a third independent reviewer (KC).

\section{Risk of bias assessment}

The Cochrane Collaboration Risk of Bias tool for Clinical Trials was used to appraise risk of bias. Included studies were rated by two independent reviewers (MB, MJS). Any disagreements between reviewers were discussed in a consensus meeting and an independent arbitrator (JK) was employed when consensus could not be met. Agreement between raters was determined using Cohen's Kappa ( $\kappa)$. If risk of bias was high in $>$ three out of five categories, overall study risk was rated as high, if risk was high in three out of five categories, study risk was moderate and if risk was high in <three out of five categories, overall study risk was rated as low. ${ }^{20}$ All studies were included in subsequent analyses, and sensitivity analyses were performed as appropriate.

\section{Data extraction, synthesis and analyses}

All potential references were imported into Endnote X7 (Thomson Reuters, Carlsbad, California, USA) and duplicates removed. Data were extracted by two independent reviewers (JK, ABM). Any discrepancies in data extraction were resolved by an independent arbitrator (KC).

Findings were summarised and population characteristics (age, gender, type and description of hip OA, duration of symptoms), and details of outcome measures, length of follow-up and type intervention undertaken were collated. We have reported main findings only for studies where the physiotherapist-led intervention was compared with a comparator/control intervention (RCT design) in order to ensure only higher quality evidence was included.

For studies of RCT design, follow-up scores were compared with the published Patient Acceptable Symptom State (PASS) scores for that outcome (if known) and change scores were compared with the published minimal important change (MIC) score for that outcome (if known). The proportion of people who achieve a PASS from follow-up scores was estimated using previously published methods, incorporating means, SD, sample size and z-scores. ${ }^{21}$ Previously published relevant PASS scores include 88 points (Hip Osteoarthritis and disability Outcome Score (HOOS)-pain) ${ }^{22}$ and 83 points (HOOS-quality of life $(\mathrm{QOL}))^{22}$ 1-year posthip arthroplasty; 58 points (International Hip Outcome Tool (IHOT)-33) ${ }^{23} 1-5$ years posthip arthroscopy and 98 points (Hip Outcome Score (HOS)-activity of daily living $(\mathrm{ADL}))^{24}$ and 94 points (HOS-Sport) ${ }^{24} 1$-year posthip arthroscopy. Previously published MIC scores include 9 points (HOOS-pain), ${ }^{25} 11$ points (HOOS-QOL), ${ }^{25} 10$ points (IHOT$33)^{25} 1-2$ years posthip arthroscopy; 15 points (HOS-ADL) ${ }^{24}$ 1 -year posthip arthroscopy and 28 points (HOS-Sport) 6 months posthip arthroscopy. ${ }^{24}$

Data analyses were conducted by two investigators (AIS and JK). The 'meta' package (V.4.9-5), from the R statistical software package (V.3.5.1) was used to calculate relevant effect sizes, produce forest plots and pool data in a meta-analysis where relevant (https://www.r-project.org/). Standardised mean differences (SMD) were calculated for the studies of RCT design, to determine the magnitude of the effect of any interventions within groups or between groups. Where data were deemed statistically and clinically homogenous, meta-analyses were undertaken using a random effects model. In order to undertake SMD calculations in studies where non-normally distributed data were presented, the IQR was calculated. ${ }^{26}$ For analysis of outcomes that reported within group (pre-intervention to post-intervention), the 
standardised paired difference (SPD) was calculated from the sample size, mean and SD of the difference from pre-intervention to post-intervention time points. An additional requirement for SPD calculation was to account for the within-person correlation (r) between the two time points. If between-limb correlation was not reported, a conservative estimate of $r=0.5$ was used. ${ }^{27}$ Standardised mean/paired difference magnitude was interpreted as: $\geq 0.8$ large effect; $0.5-0.79$ moderate effect and 0.2-0.49 weak effect. ${ }^{28}$ Where SMDs could not be calculated, study conclusions were presented in tables, and best evidence synthesis was performed. For the best evidence synthesis, evidence was categorised as 'strong' if there were multiple high-quality clinical trials or cohort studies; 'moderate' if there was either one high-quality clinical trial or cohort study and more than two high-quality case-control studies or pilot clinical trials, or more than three high-quality case-control studies; 'limited' if there were either one or two case-control studies or pilot clinical trials, or multiple cross-sectional studies and 'insufficient' if there was not more than one cross-sectional study. ${ }^{20}$ All data used in calculations of

SMDs and SPDs have been shared publicly at Figshare (https:// figshare.com/s/d18bcb066f1de48861cf).

\section{RESULTS}

\section{Search strategy}

The search yielded 1722 titles and abstracts for screening. Sixtyfive full texts were screened and 51 were excluded. There were 14 papers in the final analyses. An overview of the study identification process is provided in figure 1 . Characteristics of the included studies are presented in table 1 . The number of studies excluded along with reasons is provided in online supplementary appendix 2 .

\section{Risk of bias}

Online supplementary appendix 3 contains the results of risk of bias assessment using the Cochrane Risk of Bias Tool. Agreement between raters occurred on 54 out of 70 items, where $\kappa=0.65$, which represents moderate agreement. ${ }^{29}$ Following discussion, consensus was obtained for all items. Overall results for the
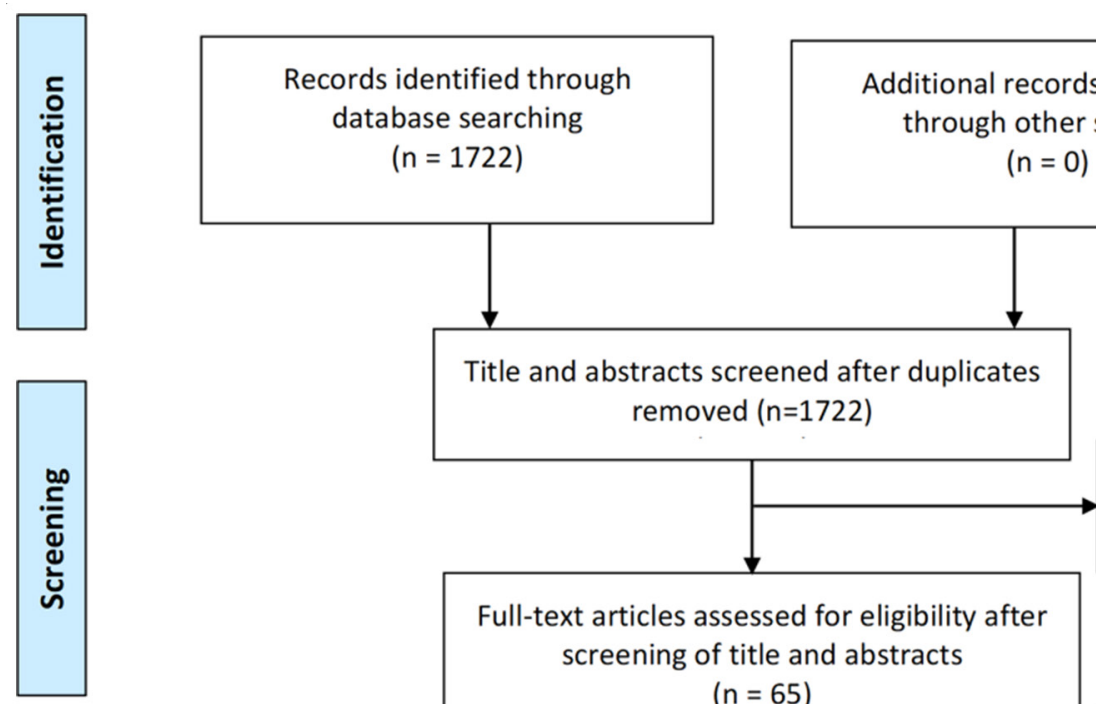

Records excluded

( $n=1657$ )

Full-text articles assessed for eligibility after screening of title and abstracts

$(n=65)$
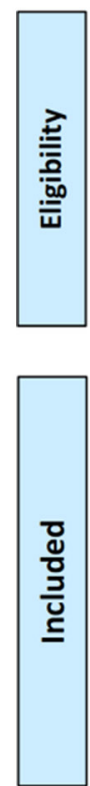

Additional records identified through other sources

$(n=0)$

Figure 1 Preferred Reporting Items for Systematic Reviews and Meta-Analyses flow chart of study inclusion. RCT, randomised controlled trial. 


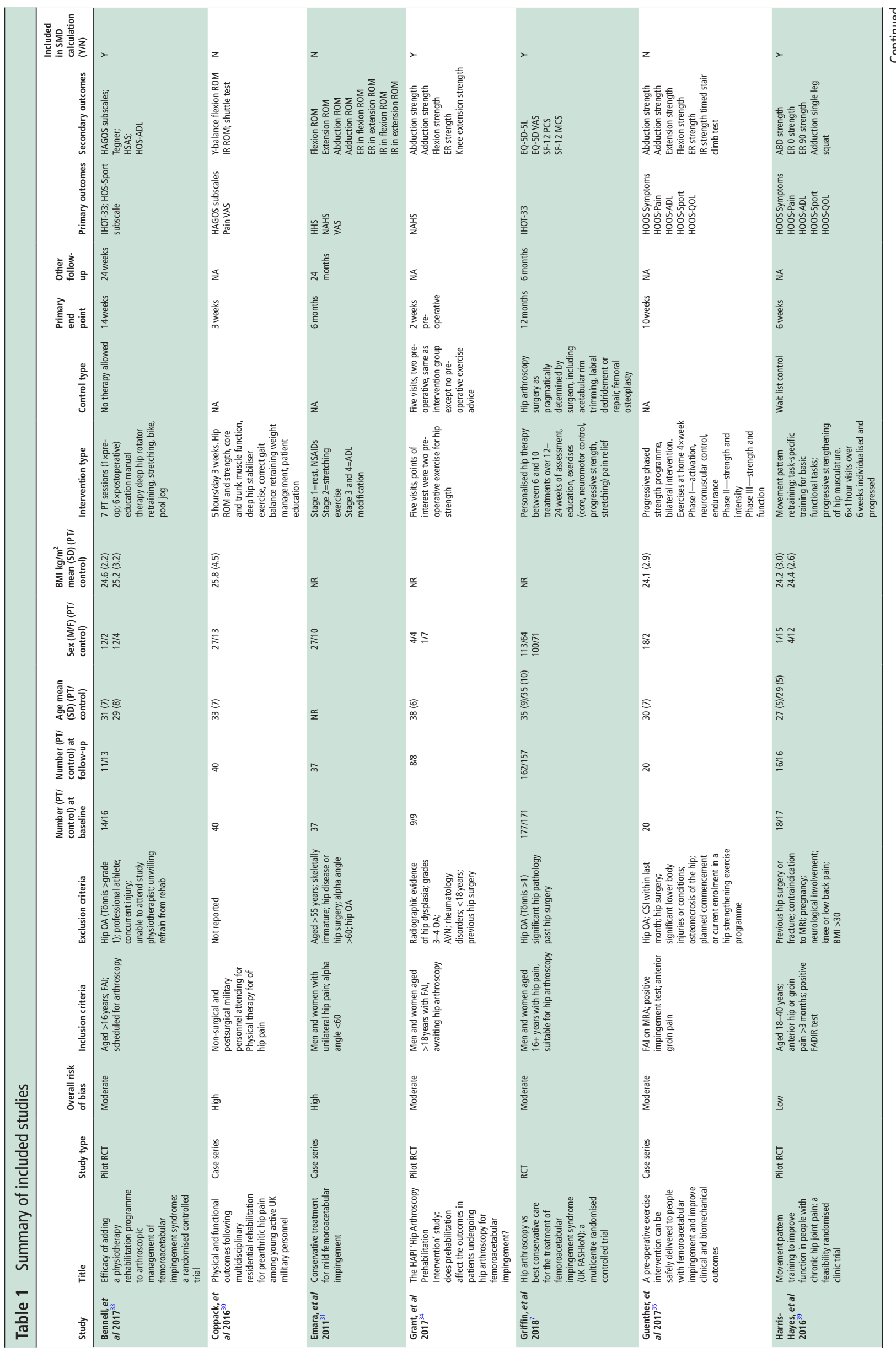




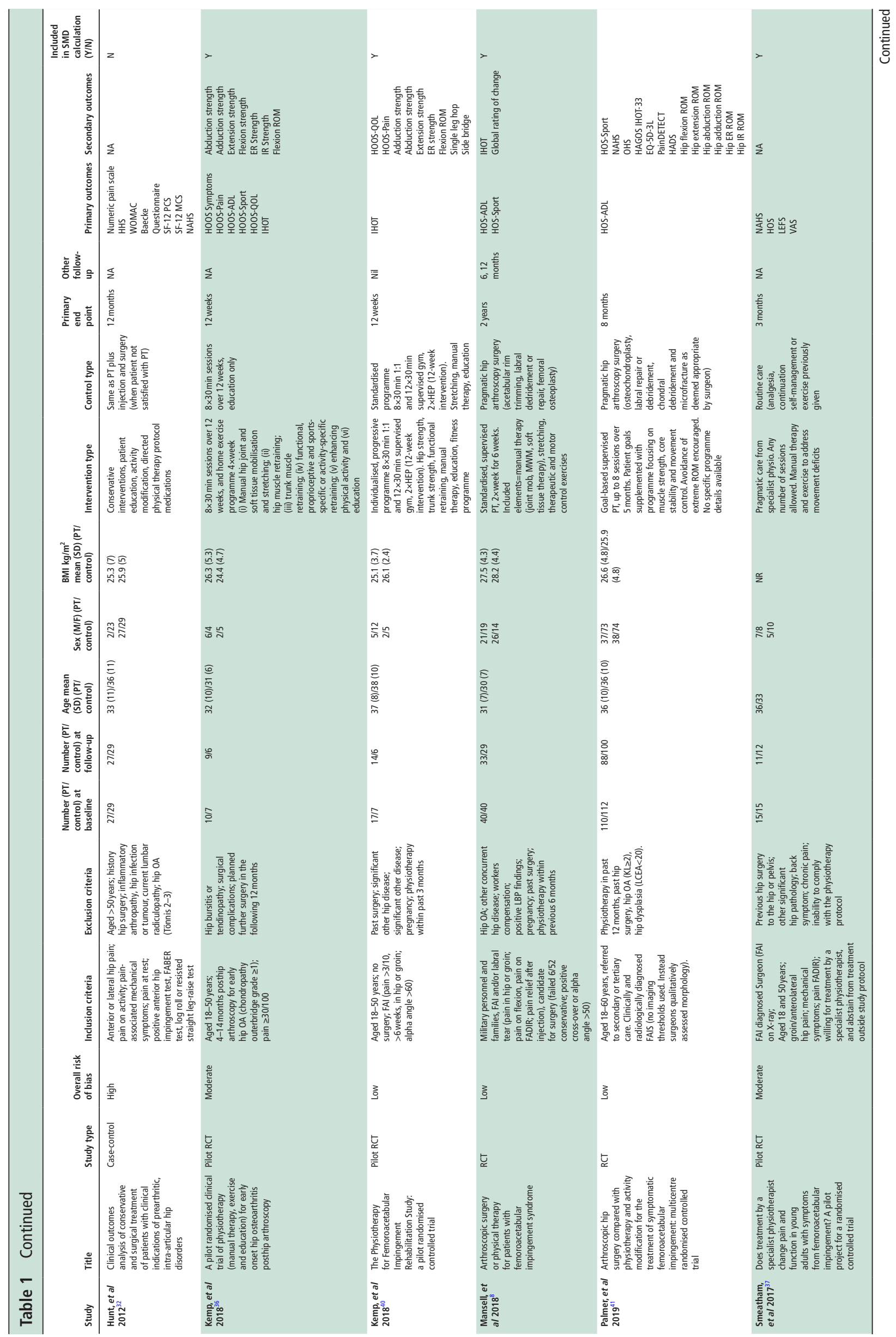

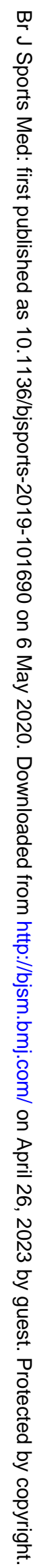




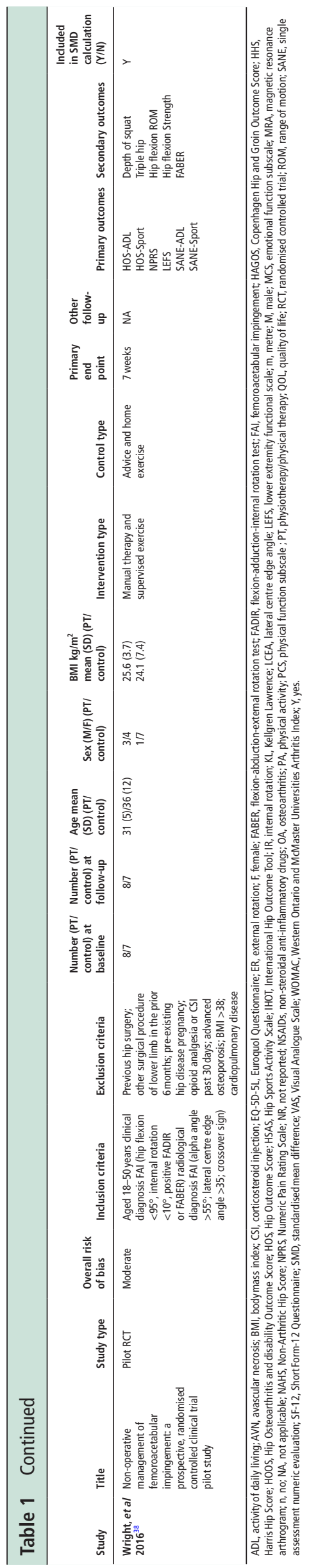

risk of bias assessment are mentioned in table 1 . Three studies had a high risk of bias, ${ }^{30-32}$ seven studies had a moderate risk of bias $^{733-38}$ and four studies had a low risk of bias. ${ }^{89-41}$ In the included studies, the overall risk of performance bias (blinding of participants and personnel) and detection bias (blinding of outcome assessors) was high (high in $\geq$ nine studies); the risk of attrition bias (incomplete outcome data) and the risk of selection bias (random sequence generation and allocation concealment) was moderate (high in six to eight studies) and the risk of reporting bias (selective reporting of outcomes) was low (high in $<$ six studies).

\section{Participants}

The 14 included studies contained 542 patients (283 men, 259 women) with sample sizes of the physiotherapist-led intervention groups ranging from 8 patients $^{38}$ to 177 patients. ${ }^{7}$ Ten studies were of RCT design. Mean participant age ranged from 27 to 38 years, while the mean body mass index (BMI) ranged from 24.1 to $27.5 \mathrm{~kg} / \mathrm{m}^{2}$. Ten studies included participants based on a diagnosis of FAI syndrome, $810303133-3537384041$ with the remaining four studies including subjects based on a diagnosis of hip pain. ${ }^{30} 323639$ Methods used for diagnostic inclusion criteria comprised surgical findings, ${ }^{28}$ clinical examination

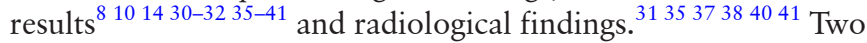
studies did not specify how FAI syndrome was diagnosed for inclusion $^{33} 34$ (table 1). One study provided information about level of sports/physical activity, ${ }^{41}$ and no study provided detail about the duration of symptoms.

\section{Outcomes measured}

All included studies used a patient-reported outcome measure (PROM) as the primary outcome measure, but there was large heterogeneity in the PROMs used. The PROMs used included: the IHOT-33, the Copenhagen Hip and Groin Outcome Score (HAGOS), HOOS, the Oxford Hip Score (OHS), the NonArthritic Hip Score (NAHS), HOS, the Harris Hip Score (HHS), a pain Visual Analogue Scale (VAS), a Numeric Pain Rating Scale (NPRS), the Hip Sports Activity Scale (HSAS), a Global Rating of Change (GROC) score, the Hospital Anxiety and Depression Scale (HADS), the University of California, Los Angeles (UCLA) activity score, the European Quality of Life-5 Dimensions (EQ5D) and the 36-item Short Form survey (SF-36) score.

Secondary outcomes measured were mostly measures of physical function, and included: hip muscle strength, trunk muscle strength, standardised hopping tests, measures of performance on a double-leg and single-leg squat, hip range of motion tests, the timed stair climb test and the Y-balance test. The methods used to measure these impairment-based outcomes varied widely between studies. Primary follow-up time points also varied and ranged from 3 weeks $^{30}$ to 2 years. ${ }^{8}$ Most studies undertook a 3-month primary follow-up period (table 1).

\section{Physiotherapist-led interventions performed}

Seven studies included participants who had not undergone hip surgery, ${ }^{31} 3235$ 37-40 while three studies examined physiotherapist-led interventions posthip arthroscopy surgery, ${ }^{33} 3436$ one study included both postsurgical and non-surgical participants ${ }^{30}$ and three studies compared physiotherapist-led interventions to hip arthroscopic surgery. ${ }^{7841}$ The duration of physiotherapist-led interventions ranged from 3 weeks ${ }^{30}$ to 5 months. ${ }^{34} 41$

There was a large variety in the types of physiotherapist-led interventions performed. Nine studies included a strengthening programme, ${ }^{7} 103034-37$ 39-41 four studies included stretching/ 
ROM exercises, , 81031 five included 'core stability', 730383941 eight studies included manual therapy, $830333436-3840$ two studies included cardiovascular and return to sport retraining, ${ }^{33} 40$ two studies included functional retraining ${ }^{39} 40$ and six studies included neuromotor control exercises ${ }^{7830363839}$ (table 1). Five studies did not report the interventions in sufficient detail to allow replication of the interventions. ${ }^{30-32} 3741$

There was large heterogeneity in the control/comparator interventions used in the $10 \mathrm{RCTs}$. Control/comparator interventions used included (i) sham treatments, such as exclusion of pre-operative exercise advice, ${ }^{34}$ a standardised minimal intervention, ${ }^{40}$ education only, ${ }^{36}$ usual care (including medication and continuation of previous exercises $)^{37}$ and a home-based unsupervised exercise programme ${ }^{38}$; (ii) no-treatment group $^{33}$ or waiting-list control group ${ }^{39}$ and (iii) hip arthroscopy surgery ${ }^{7841}$ (table 1).

\section{Main findings}

Between-group differences were generated for physiotherapist-led interventions compared with the comparator intervention in four studies in patients who had not undergone surgery $^{37-40}$; in three studies posthip arthroscopy ${ }^{33} 3436$ and compared with hip arthroscopic surgery ${ }^{784}$ in three studies (table 2).

Between-group comparisons of physiotherapist-led interventions compared with sham/no treatment in non-surgical patients

The level of evidence was limited, with two high-quality ${ }^{39} 40$ and two moderate-quality ${ }^{37}$ pilot RCTs included. In patients with hip pain (non-surgical), physiotherapist-led interventions of 3 months duration that included targeted strengthening programmes showed moderate pooled effects for function (SMD (95\% CI): 0.66 (0.09 to 1.23$)$ ) favouring the physiotherapist-led intervention group ${ }^{37} 40$ (figure 2). For physiotherapist-led interventions of shorter duration (6-8 weeks), effects showed no significant differences between groups (figure 3). One study achieved a follow-up score greater than the PASS score, and change score greater than the MIC for the primary outcome. ${ }^{40}$

\section{Between-group comparisons of physiotherapist-led interventions} compared with sham/no treatment in post-hip arthroscopy patients The level of evidence was limited, with two moderate-quality pilot RCTs included. ${ }^{33} 36$ Data could not be pooled due to heterogeneity in outcomes assessed. Moderate positive effects for patient-reported function $(0.67 ; 95 \%$ CI 0.07 to 1.26$)$ were reported in the two RCTs, favouring the physiotherapist-led interventions (figure 4). Both studies achieved a follow-up score greater than the PASS score and change score greater than the MIC for the primary outcome. The proportion of participants undertaking physiotherapist-led interventions achieving a score greater than the PASS score ranged from $11 \%{ }^{36}$ to $90 \%$. $^{33}$

\section{Between-group comparisons of physiotherapist-led interventions} compared with hip arthroscopic treatment

The level of evidence was strong, with two high-quality $\mathrm{RCTs}^{841}$ and one moderate-quality $\mathrm{RCT}^{7}$ included (figure 5). In studies comparing physiotherapist-led interventions with hip arthroscopic surgery, at 8-12 months, weak positive pooled effects $(-0.32 ; 95 \%$ CI -0.57 to -0.07$)$ favoured hip arthroscopy surgery. At 24 months, there was only one moderate-quality RCT and thus the level of evidence is limited. There was no significant difference between groups $(-0.18$; 95\% CI -0.64 to 0.28$)$. For the physiotherapist-led intervention groups, no studies achieved a follow-up score greater than the PASS score, and only one study had a change score greater than the MIC for the primary outcome. ${ }^{7}$ The proportion of participants undertaking physiotherapist-led interventions achieving a score greater than the PASS score ranged from $7 \%{ }^{41}$ to $37 \%$.

Within-group change for patient-reported outcome measures for physiotherapist-led interventions in non-operative patient groups Within-group effects for physiotherapist-led interventions on PROMS in patients with hip pain were able to be calculated for nine of the included studies ${ }^{78} 30-323^{37-40}$ (table 3). The level of evidence overall was moderate, with one high-quality RCT and several high-quality pilot RCTs included in the analyses. Positive SPDs ranged from moderate effects for patient-reported function $(0.57 ; 95 \% \text { CI } 0.03 \text { to } 1.12)^{37}$ following a 3 -month intervention, to large positive effects for function $(3.85 ; 95 \%$ CI 2.91 to 4.78$)^{31}$ following a 6 -month intervention. Data were not able to be pooled due to heterogeneity between time points and the outcomes measured. The proportion of participants undertaking physiotherapist-led interventions achieving a score greater than the PASS score ranged from $25 \%{ }^{3839}$ to $86 \% .^{40}$

Within-group change for physical impairments for physiotherapistled interventions in non-operative patient groups

Nine studies reported the effects of physiotherapist-led interventions on physical impairments on people with hip pain ${ }^{3031343537-41}$ (table 3), with SPDs able to be calculated for seven of the nine studies. The level of evidence was limited, with no high-quality, full-scale RCTs included in any of the analyses relating to physical impairments. The impairment measures included hip range of motion,,$^{30313840}$ hip muscle strength, ${ }^{35}{ }^{38-40}$ depth of squat, ${ }^{38}$ balance, ${ }^{30}$ trunk endurance, ${ }^{40}$ control during single leg squat ${ }^{39}$ and hopping performance. ${ }^{3840}$ Data were not able to be pooled for within-group change in physical impairment measures, due to heterogeneity between time points and the methods by which outcomes were measured.

For hip flexion range of motion, SPDs varied, and ranged from large negative changes $(2.07,95 \%$ CI -2.64 to -1.50$)$ following a 6-month intervention consisting of rest, stretching and activity modification ${ }^{31}$ to large positive change $(1.08,95 \%$ CI 0.49 to 1.68 ) following a 3 -month intervention comprising strengthening exercise, manual therapy and education. ${ }^{40}$

Hip muscle strength was recorded in four studies, ${ }^{35} 38-40$ and SPDs ranged from weak, non-significant effects $(0.09,-0.35$ to 0.53 ) for an 10 week intervention comprising progressive strengthening exercises, ${ }^{35}$ to large positive SMDs (1.19, 0.57 to 1.81) for a 12 week intervention comprising targeted strengthening and functional retraining exercises. ${ }^{40}$

There were varied within-group changes in functional task performance. Positive SPDs ranged from moderate improvements in the timed stair climb test $(0.57,95 \%$ CI 0.10 to 1.05$){ }^{35}$ single-leg hop test $(0.65,95 \% \text { CI } 0.12 \text { to } 1.17)^{40}$ and Y-balance test $(0.63,95 \% \text { CI } 0.29 \text { to } 0.97)^{30}$ with movement retraining and functional exercise programmes, to large improvements for trunk endurance $(0.95,95 \%$ CI 0.38 to 1.53$)$ following a 3 -month targeted trunk-strengthening programme. ${ }^{40}$

\section{DISCUSSION}

Our systematic review evaluated the effectiveness of physiotherapist-led interventions to improve pain and function in young and middle-aged adults experiencing hip-related pain, including those with FAI syndrome. The 14 studies included 7 pilot and 3 full-scale RCTs, and demonstrated considerable variability in 


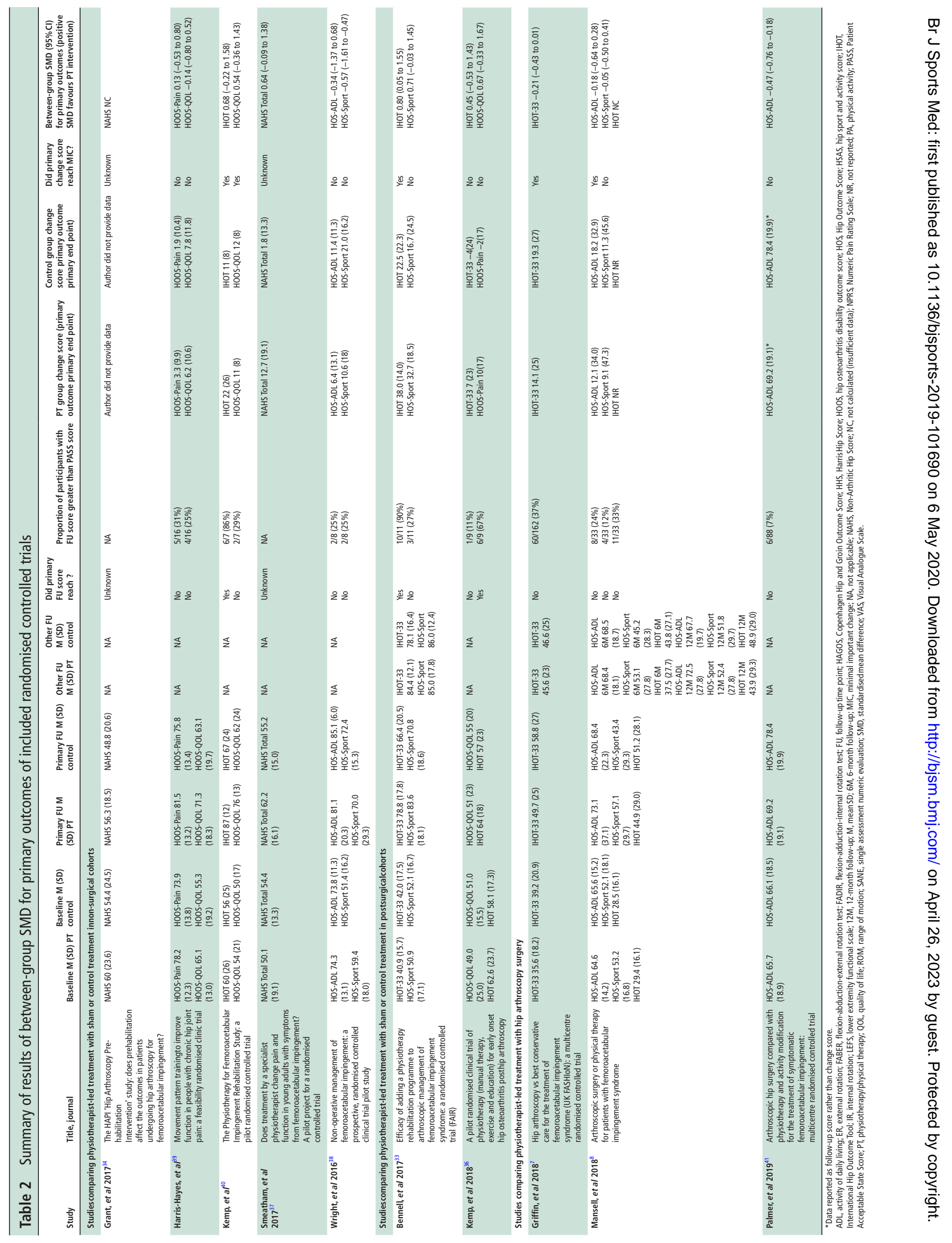




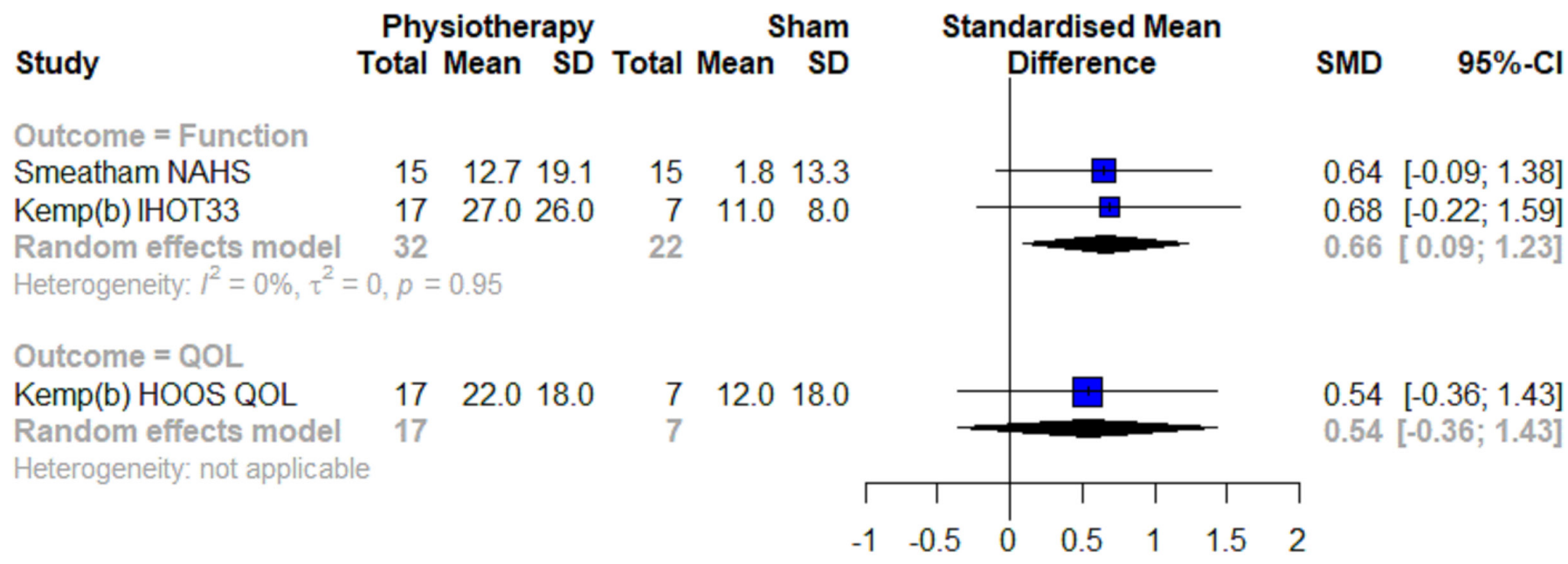

\section{Favours Sham Favours Physiotherapy}

Figure 2 Between-group differences for physiotherapist-led treatment compared with sham/no treatment in non-surgical populations at 3 months follow-up. HOOS, Hip Osteoarthritis and disability Outcome Score; IHOT, International Hip Outcome Tool; QOL, quality of life; SMD, standardised mean difference; total, number of participants.

the risk of bias, the outcomes reported and the interventions performed, which limited opportunities for meta-analysis. Included studies had poor transparency in reporting of interventions, inconsistency in PROMs and methods used to measure physical impairments.

Our findings suggest that in people with hip pain, physiotherapist-led interventions may improve function and strength, however the effects on pain and QOL were unclear. There was limited evidence that interventions with targeted strengthening exercise programmes that were at least 3 months duration might have the best effect. Hip arthroscopy surgery had a small positive benefit compared with a physiotherapist-led intervention at 8-12 months. At 24 months, the level of evidence was limited indicating no difference between the hip arthroscopy surgery and physiotherapist-led interventions. Very few of the physiotherapist-led interventions in this review achieved follow-up and change scores that surpassed previously published PASS and MIC scores.

Physiotherapist-led interventions for those who had and had not undergone hip arthroscopy surgery for hip pain primarily comprised exercise therapy, where the types of exercise described included strength training, movement pattern retraining, range of motion exercises and stretching. However, specific details of the programmes were rarely well described. The moderate effect observed for these interventions were hampered by small sample sizes and require full-scale RCTs to confirm findings. Extending the outcome measurement beyond the 3-month mark would determine whether improvements seen would be maintained in the medium-term to long-term. A recent consensus meeting reported considerable discord in the type, duration, intensity and modality of posthip arthroscopy rehabilitation provided by physiotherapists. ${ }^{42}$ The consensus group suggested that full-scale RCTs are required in order to gain clarification on the composition of optimal postarthroscopic rehabilitation programmes. ${ }^{42}$

Physiotherapist-led intervention was inferior to hip arthroscopy surgery with small between-groups differences at 12-month follow-up. ${ }^{741}$ Not surprisingly, despite the small difference favouring surgery, physiotherapy was far more costeffective ( $£ 155$ for physiotherapist-led treatment compared with $£ 2372$ for hip arthroscopy). ${ }^{7}$ Arthroscopic surgery could be recommended as a second-line treatment for patients who have not responded adequately to a physiotherapist-led treatment programme. ${ }^{42}$ However, the mean effects beyond that of physiotherapy were weak and may not be clinically meaningful.

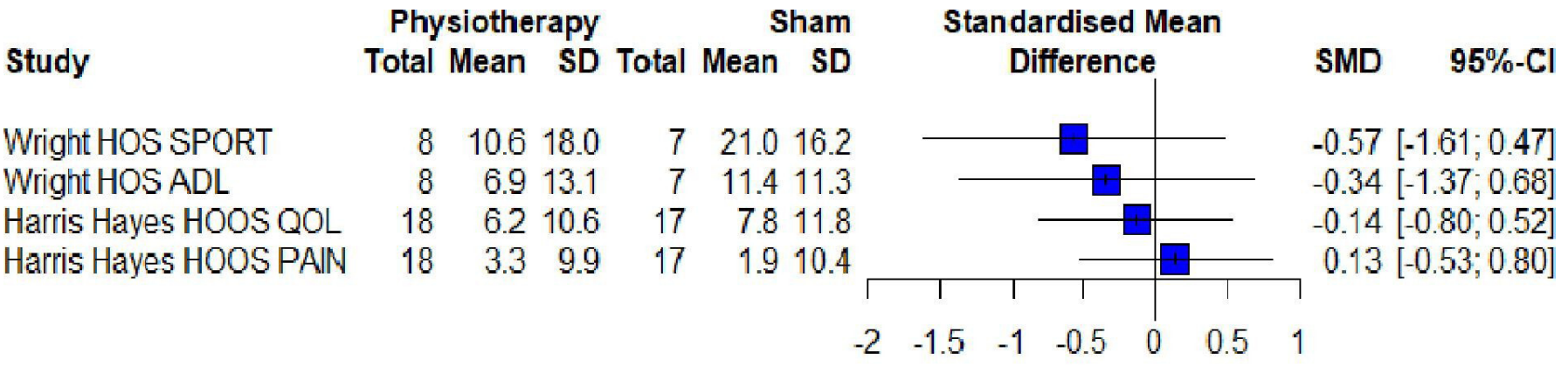

Favours Sham Favours Physiotherapy

Figure 3 Between-group differences for physiotherapist-led treatment compared with sham/no treatment in non-surgical populations at 6 weeks follow-up.ADL, Activity of Daily Living; HOOS, Hip Osteoarthritis and disability Outcome Score; HOS, Hip Outcome Score; QOL, quality of life; SMD, standardised mean difference; total, number of participants. 


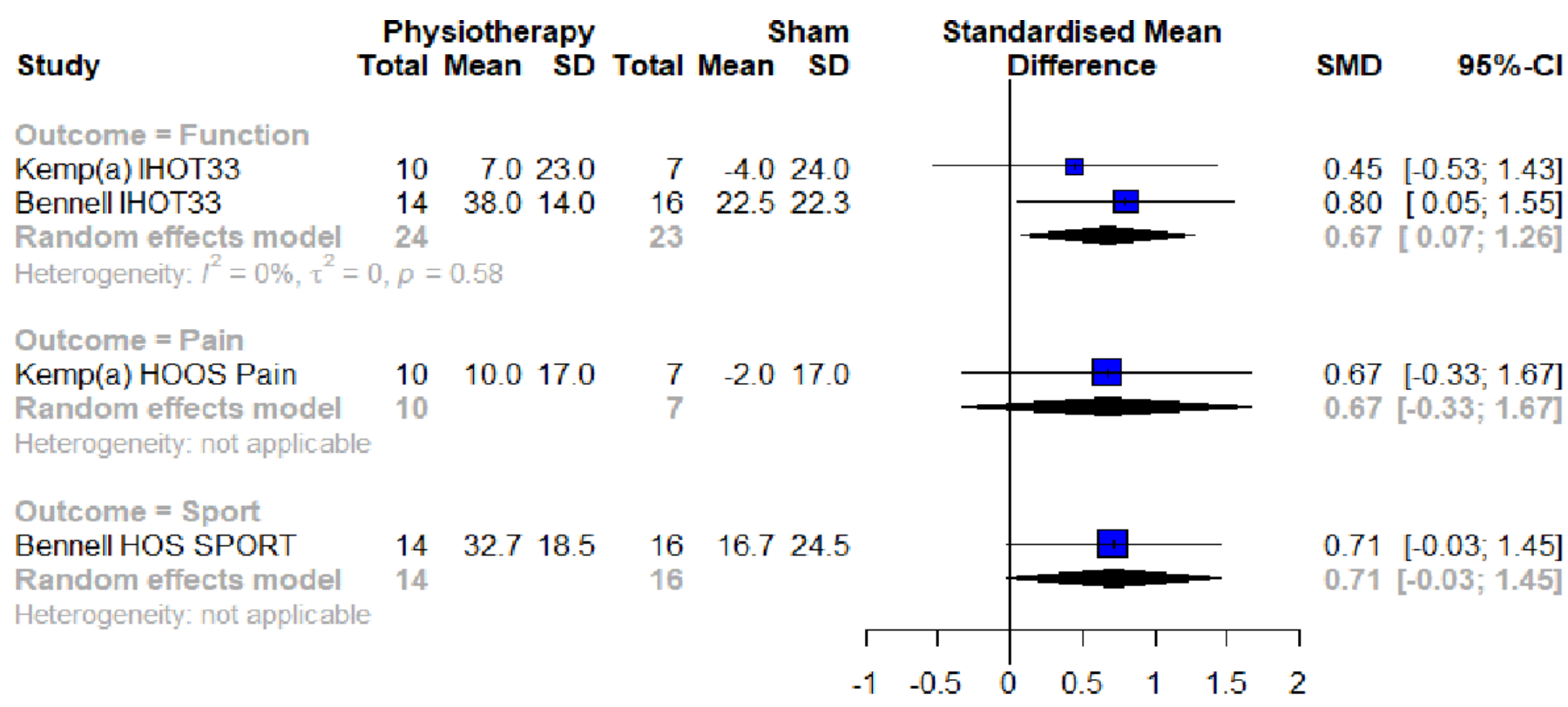

Favours Sham Favours Physiotherapy

Figure 4 Between-group differences for physiotherapist-led treatment compared with sham/no treatment in posthip arthroscopy populations at 3-month follow-up. HOOS, Hip Osteoarthritis and disability Outcome Score; HOS, Hip Outcome Score; IHOT, International Hip Outcome Tool; SMD, standardised mean difference; total, number of participants.

The within-group improvements for the physiotherapist-led interventions in these studies were modest, with only one study achieving the PASS, and they may not represent optimal treatment. ${ }^{18}$ Further studies might shed more light on the relative effectiveness of surgery and physiotherapy particularly in the medium-term and long-term. ${ }^{43}$

Multimodal, physiotherapist-led interventions, ${ }^{7} 830333436-3840$ including exercise therapy combined with manual therapy, medication, activity modification, advice and education, were most commonly studied. Manual therapy is effective when combined with exercise for hip OA, ${ }^{44}$ but there is debate whether contemporary physiotherapist-led interventions for musculoskeletal pain should include multimodal treatment additions such as manual therapy. ${ }^{42}$ Further studies are required to confirm whether additional treatment elements, such as manual therapy, impart a greater benefit than exercise-therapy alone for young and middle-aged adults with hip pain.

Physiotherapist-led interventions on physical impairments had variable effects. For hip range of motion, the largest positive effects pre-physiotherapist-led to post-physiotherapist-led treatment were seen following a 3-month intervention strengthening exercise, manual therapy and education. ${ }^{40}$ The greatest

\section{Study \\ Physiotherapy Arthroscopy Total Mean SD Total Mean SD}

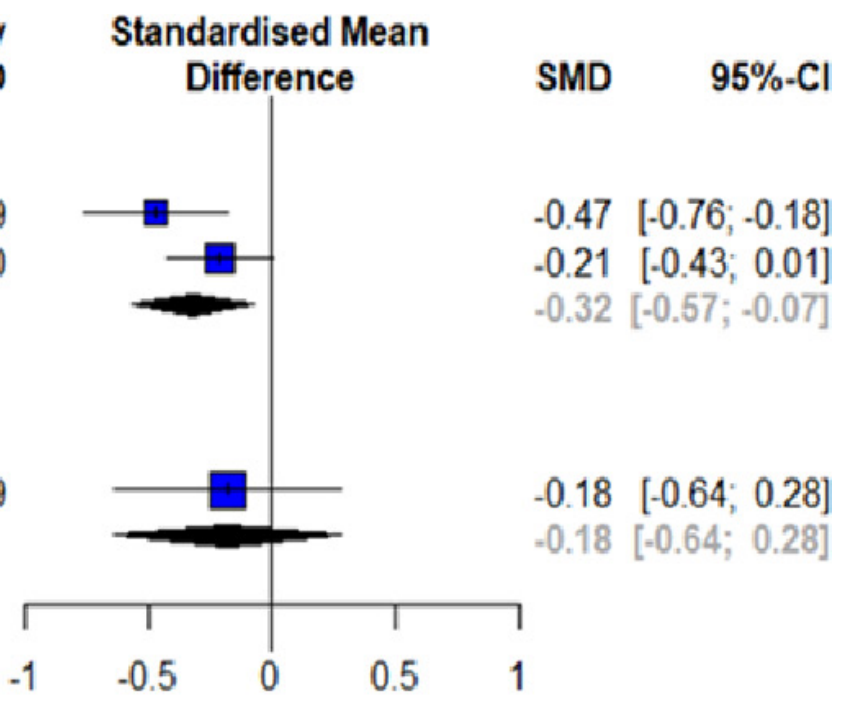

Time Point $=6-12$ Months

$\begin{array}{lrrrr}\text { Palmer HOS ADL } & 88 & 69.2 & 19.1 & 100 \\ \text { Griffin IHOT33 } & 163 & 14.1 & 25.0 & 158 \\ \text { Random effects model } & 251 & & 258 \\ \text { Heterogeneity } l^{2}=48 \%, \tau^{2}=0.0161, \rho=0.16 & \end{array}$

\section{Time Point $=24$ months}

Mansell HOS ADL $\begin{array}{lll}37 & 12.1 & 34.0\end{array}$ 37 Random effects model 37 37 18.232 .9 Heterogeneity: not applicable

78.419 .9 19.627 .0

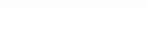


Table 3 Summary of results of within-group standardised paired differences for physiotherapist-led treatment in non-operative patients (randomised and non-randomised studies)

\begin{tabular}{|c|c|c|c|}
\hline Study & Title & Baseline M (SD) PT & Prim FU M (SD) PT \\
\hline \multicolumn{4}{|c|}{ Randomised studies } \\
\hline $\begin{array}{l}\text { Grant, et al } \\
2017^{34}\end{array}$ & $\begin{array}{l}\text { The HAPI 'Hip Arthroscopy Pre- } \\
\text { habilitation } \\
\text { Intervention' study: does prehabilitation } \\
\text { affect the outcomes in patients } \\
\text { undergoing hip arthroscopy for } \\
\text { femoroacetabular impingement? }\end{array}$ & $\begin{array}{l}\text { Abduction strength } 16.6(11.8 \\
\text { Adduction strength } 13.4(4.8) \\
\text { Flexion strength } 27.3(23.1) \\
\text { ER strength } 15.3(5.3) \\
\text { Knee extension strength } 37.1(23.0)\end{array}$ & $\begin{array}{l}\text { Abduction strength } 20.9(11.6) \\
\text { Adduction strength } 19.3(9.9) \\
\text { Flexion strength } 32.9(16.6) \\
\text { External rotation strength } 19.0(6.3) \\
\text { Knee extension strength } 49.0(40.2)\end{array}$ \\
\hline
\end{tabular}

Within-group SPD $(95 \% \mathrm{Cl})$ for primary outcomes (positive SPD favours postintervention improvement)

undergoing hip arthroscopy for

Knee extension strength $49.0(40.2)$

Abduction strength not calculated as follow-up dataset not complete

Adduction strength not calculated as follow-up dataset not complete

Flexion strength not calculated as follow-up dataset not complete

External rotation strength not calculated as follow-up dataset not complete

Knee extension strength not calculated as follow-up dataset not complete

\begin{tabular}{|c|c|c|c|c|}
\hline $\begin{array}{l}\text { Griffin, et al } \\
2018^{7}\end{array}$ & $\begin{array}{l}\text { Hip arthroscopy vs best conservative } \\
\text { care for the treatment of } \\
\text { femoroacetabular impingement } \\
\text { syndrome (UK FASHloN): a multicentre } \\
\text { randomised controlled trial }\end{array}$ & IHOT-33 35.6 (18.2) & IHOT-33 49.7 (25) & IHOT-33 0.63 (0.46 to 0.79$)$ \\
\hline $\begin{array}{l}\text { Harris-Hayes, } \\
\text { et al } 2016^{39}\end{array}$ & $\begin{array}{l}\text { Movement pattern training to improve } \\
\text { function in people with chronic hip joint } \\
\text { pain: a feasibility randomised clinic trial }\end{array}$ & $\begin{array}{l}\text { HOOS Symptoms } 75.0(17.0) \\
\text { HOOS-Pain } 78.2(12.3) \\
\text { HOOS-ADL } 90.7(9.9) \\
\text { HOOS-Sport } 77.1(17.5) \\
\text { HOOS-QOL } 65.1(13.0) \\
\text { Abduction strength } 6.7(1.8) \\
\text { ER } 0 \text { strength } 2.9(0.9) \\
\text { ER } 90 \text { strength } 3.4(0.8) \\
\text { Flexion in single leg squat } 67.4(14.0) \\
\text { Adduction in single leg squat } 20.2(6.6) \\
\text { IR in single leg squat } 2.5(7.7)\end{array}$ & $\begin{array}{l}\text { HOOS Symptoms } 85.0(13.6) \\
\text { HOOS-Pain } 81.5(13.2) \\
\text { HOOS-ADL } 93.5(10.9) \\
\text { HOOS SP } 84.6(19.6) \\
\text { HOOS-QOL } 71.3(18.3) \\
\text { Abduction strength } 7.2(2.3) \\
\text { ER } 0 \text { strength3.2 (0.8) } \\
\text { ER } 90 \text { strength } 3.9(0.9) \\
\text { Flexion in single leg squat } 61.7(15.9) \\
\text { Adduction in single leg squat17.6 (5.7) } \\
\text { IR in single leg squat 2.7(6.3) }\end{array}$ & $\begin{array}{l}\text { HOOS Symptoms } 0.61 \text { ( } 0.11 \text { to } 1.12) \\
\text { HOOS-Pain } 0.25(-0.22 \text { to } 0.72) \\
\text { HOOS-ADL } 0.26(-0.21 \text { to } 0.73) \\
\text { HOOS SP } 0.38(-0.09 \text { to } 0.86) \\
\text { HOOS-QOL } 0.36 \text { ( }-0.11 \text { to } 0.84) \\
\text { Abduction strength } 0.23(-0.24 \text { to } 0.70) \\
\text { ER } 0 \text { strength } 0.10(-0.36 \text { to } 0.56) \\
\text { ER } 90 \text { strength } 0.78 \text { ( } 0.25 \text { to } 1.31) \\
\text { Flexion in single leg squat } 0.36(0.11 \text { to } 0.84) \\
\text { Adduction in single leg squat } 0.40(-0.08 \text { to } 0.88) \\
\text { IR in single leg squat }-0.02(-0.49 \text { to } 0.44)\end{array}$ \\
\hline $\begin{array}{l}\text { Kemp et al, } \\
2018^{40}\end{array}$ & $\begin{array}{l}\text { The Physiotherapy for } \\
\text { Femoroacetabular Impingement } \\
\text { Rehabilitation Study: a pilot } \\
\text { randomised controlled trial }\end{array}$ & $\begin{array}{l}\text { IHOT } 60(26) \\
\text { HOOS-QOL } 54(21) \\
\text { Adduction strength } 0.85(0.17) \\
\text { Abduction strength } 0.94(0.23) \\
\text { Extension } 0.92(0.28) \\
\text { ER strength0.48 }(0.11) \\
\text { Flexion ROM } 109(14) \\
\text { Single leg hop } 1.14(0.26) \\
\text { Side bridge 59(42) }\end{array}$ & $\begin{array}{l}\text { IHOT 87(12) } \\
\text { HOOS-QOL 76(13) } \\
\text { Adduction strength } 1.1(0.22) \\
\text { Abduction strength } 1.16(0.23) \\
\text { Extension strength } 1.17(0.32) \\
\text { ER strength } 0.57(0.19) \\
\text { Flexion ROM 123(9) } \\
\text { Single leg hop 1.34 (0.32) } \\
\text { Side bridge 98(35) }\end{array}$ & $\begin{array}{l}\text { IHOT } 1.14 \text { ( } 0.53 \text { to } 1.75) \\
\text { HOOS-QOL } 1.14 \text { (0.53 to } 1.75) \\
\text { Adduction strength } 1.19(0.57 \text { to } 1.81) \\
\text { Abduction strength } 0.91(0.35 \text { to } 1.48) \\
\text { Extension strength } 0.79(0.24 \text { to } 1.33) \\
\text { ER strength } 0.52(0.01 \text { to } 1.03) \\
\text { Flexion ROM } 1.08(0.49 \text { to } 1.68) \\
\text { Single leg hop } 0.65(0.12 \text { to } 1.17) \\
\text { Side bridge } 0.95 \text { (0.38 to } 1.53)\end{array}$ \\
\hline $\begin{array}{l}\text { Mansell, et al } \\
2018^{8}\end{array}$ & $\begin{array}{l}\text { Arthroscopic surgery or physical therapy } \\
\text { for patients with femoroacetabular } \\
\text { impingement syndrome }\end{array}$ & $\begin{array}{l}\text { HOS-ADL } 64.6(14.2) \\
\text { HOS-Sport } 53.2(16.8)\end{array}$ & $\begin{array}{l}\text { HOS-ADL } 73.1(37.1) \\
\text { HOS-Sport } 57.1(29.7)\end{array}$ & $\begin{array}{l}\text { HOS-ADL } 0.26(-0.06 \text { to } 0.57) \\
\text { HOS-Sport } 0.15 \text { (-0.16 to } 0.46)\end{array}$ \\
\hline $\begin{array}{l}\text { Palmer, et al } \\
2019^{41}\end{array}$ & $\begin{array}{l}\text { Arthroscopic hip surgery compared with } \\
\text { physiotherapy and activity modification } \\
\text { for the treatment of symptomatic } \\
\text { femoroacetabular impingement: } \\
\text { multicentre randomised controlled trial }\end{array}$ & $\begin{array}{l}\text { Hip Flexion ROM } 95.7(19.1) \\
\text { Hip extension ROM } 17.9(7.9) \\
\text { Hip Abduction ROM } 27.5(11.9) \\
\text { Hip adduction ROM } 21.6(7.9) \\
\text { Hip ER ROM } 25.0(11.8) \\
\text { Hip IR ROM } 24.0(11.2)\end{array}$ & $\begin{array}{l}\text { Hip Flexion ROM } 99.7(17.5) \\
\text { Hip extension ROM } 15.7(8.0) \\
\text { Hip Abduction ROM } 29.6(11.7) \\
\text { Hip adduction ROM } 23.2(8.9) \\
\text { Hip ER ROM } 27.4(9.7) \\
\text { Hip IR ROM } 28.9(11.2)\end{array}$ & $\begin{array}{l}\text { Hip Flexion ROM not calculated as follow-up dataset } \\
\text { not complete } \\
\text { Hip extension ROM not calculated as follow-up } \\
\text { dataset not complete } \\
\text { Hip Abduction ROM not calculated as follow-up } \\
\text { dataset not complete } \\
\text { Hip adduction ROM not calculated as follow-up } \\
\text { dataset not complete } \\
\text { Hip ER ROM not calculated as follow-up dataset not } \\
\text { complete } \\
\text { Hip IR ROM not calculated as follow-up dataset not } \\
\text { complete }\end{array}$ \\
\hline $\begin{array}{l}\text { Smeatham, et } \\
\text { al } 2017^{37}\end{array}$ & $\begin{array}{l}\text { Does treatment by a specialist } \\
\text { physiotherapist change pain and } \\
\text { function in young adults with } \\
\text { symptoms from femoroacetabular } \\
\text { impingement? A pilot project for a } \\
\text { randomised controlled trial }\end{array}$ & $\begin{array}{l}\text { NAHS Total } 50.1(19.1) \\
\text { HOS-ADL } 69(39) \\
\text { HOS-Sport } 51.5(19.7)\end{array}$ & $\begin{array}{l}\text { NAHS Total } 62.2(16.1) \\
\text { HOS-ADL } 90(27) \\
\text { HOS-Sport } 68(21.6)\end{array}$ & $\begin{array}{l}\text { NAHS Total } 0.64(0.09 \text { to } 1.20) \\
\text { HOS-ADL } 0.57(0.03 \text { to } 1.12) \\
\text { HOS-Sport } 0.75 \text { (0.18 to } 1.33)\end{array}$ \\
\hline $\begin{array}{l}\text { Wright, et al } \\
2016^{38}\end{array}$ & $\begin{array}{l}\text { Non-operative management of } \\
\text { femoroacetabular impingement: a } \\
\text { prospective, randomised controlled } \\
\text { clinical trial pilot study }\end{array}$ & $\begin{array}{l}\text { HOS-ADL } 74.3(13.1) \\
\text { HOS-Sport } 59.4(18.0) \\
\text { Depth squat } 54.1(12.5) \\
\text { Triple hop } 11.4(5.1) \\
\text { Flexion ROM } 100.3(20.5) \\
\text { Flexion strength } 9.9(4.2)\end{array}$ & $\begin{array}{l}\text { HOS-ADL } 81.1(20.3) \\
\text { HOS-Sport } 70.0(29.3) \\
\text { Depth squat } 43.1(15.5) \\
\text { Triple hop } 13.3(5.3) \\
\text { Flexion ROM } 122.4(18.8) \\
\text { Flexion strength } 13.2(4.4)\end{array}$ & $\begin{array}{l}\text { HOS-ADL } 0.34(-0.37 \text { to } 1.05) \\
\text { HOS-Sport } 0.37(-0.35 \text { to } 1.08) \\
\text { Depth squat } 0.69 \text { (0.08 to } 1.46) \\
\text { Triple hop } 0.32(-0.39 \text { to } 1.04) \\
\text { Flexion ROM } 1.00(0.15 \text { to } 1.84) \\
\text { Flexion strength } 0.68(-0.08 \text { to } 1.45)\end{array}$ \\
\hline \multicolumn{5}{|c|}{ Non-randomised studies } \\
\hline $\begin{array}{l}\text { Coppack, et al } \\
2016^{30}\end{array}$ & $\begin{array}{l}\text { Physical and functional outcomes } \\
\text { following multidisciplinary residential } \\
\text { rehabilitation for prearthritic hip } \\
\text { pain among young active UK military } \\
\text { personnel }\end{array}$ & $\begin{array}{l}\text { HAGOS Pain } 37.7(20.9) \\
\text { HAGOS Symptoms } 45.8(23.2) \\
\text { HAGOS ADL } 32.2(24.1) \\
\text { HAGOS Sport } 51.0(28.1) \\
\text { HAGOS PA } 84.7(24.9) \\
\text { HAGOS QOL } 69.5(24.0) \\
\text { Y BALANCE } 240.5(26.9) \\
\text { Flexion ROM } 110.2(24.3) \\
\text { IR ROM 25.2 (13.7) }\end{array}$ & $\begin{array}{l}\text { HAGOS Pain } 35.1(23.7) \\
\text { HAGOS Symptoms } 46.3(24.2) \\
\text { HAGOS ADL } 31.0(24.7) \\
\text { HAGOS Sport } 48.5(28.6) \\
\text { HAGOS PA } 77.5(31.2) \\
\text { HAGOS QOL } 64.9(23.3) \\
\text { Y BALANCE } 256.3(20.8) \\
\text { Flexion ROM 116.7 (23.3) } \\
\text { IR ROM 29.8 (12.4) }\end{array}$ & $\begin{array}{l}\text { HAGOS Pain }-0.11 \text { ( }-0.42 \text { to } 0.19) \\
\text { HAGOS Symptoms } 0.02(-0.29 \text { to } 0.33) \\
\text { HAGOS ADL }-0.05(-0.36 \text { to } 0.26) \\
\text { HAGOS Sport }-0.09(-0.40 \text { to } 0.22) \\
\text { HAGOS PA }-0.25(-0.56 \text { to } 0.07) \\
\text { HAGOS QOL }-0.19(-0.50 \text { to } 0.12) \\
\text { Y BALANCE } 0.63(0.29 \text { to } 0.97) \\
\text { Flexion ROM } 0.27(-0.05 \text { to } 0.58) \\
\text { IR ROM } 0.34(0.03 \text { to } 0.66)\end{array}$ \\
\hline
\end{tabular}




\begin{tabular}{|c|c|c|c|c|}
\hline Study & Title & Baseline M (SD) PT & Prim FU M (SD) PT & $\begin{array}{l}\text { Within-group SPD }(95 \% \mathrm{Cl}) \text { for primary outcomes } \\
\text { (positive SPD favours postintervention } \\
\text { improvement) }\end{array}$ \\
\hline $\begin{array}{l}\text { Emara, et al } \\
2011^{31}\end{array}$ & $\begin{array}{l}\text { Conservative treatment for mild } \\
\text { femoroacetabular impingement }\end{array}$ & $\begin{array}{l}\text { HHS } 72(6) \\
\text { NAHS 72(4) } \\
\text { VAS } 6(1) \\
\text { Flexion ROM } 95.0(0.4) \\
\text { Extension ROM } 4.0(1.6) \\
\text { Abduction ROM } 37.0(0.4) \\
\text { Adduction ROM } 17.0(7.0) \\
\text { ER in flexion ROM } 28.5(0.5) \\
\text { ER in extension ROM 25.3 }(0.3) \\
\text { IR in flexion ROM 9.4 (0.3) } \\
\text { IR in extension ROM } 15.8(0.4)\end{array}$ & $\begin{array}{l}\text { HHS 91(4) } \\
\text { NAHS 90(5) } \\
\text { VAS } 3(1) \\
\text { Flexion ROM } 88.0(3.5) \\
\text { Extension ROM } 3.7(2.2) \\
\text { Abduction ROM } 36.0(1.4) \\
\text { Adduction ROM } 17.0(9.0) \\
\text { ER in flexion ROM } 28.4(1.2) \\
\text { ER in extension ROM 24.5 (1.0) } \\
\text { IR in flexion ROM } 11.3(0.5) \\
\text { IR in extension ROM } 15.7(0.7)\end{array}$ & $\begin{array}{l}\text { HHS } 3.52(2.65 \text { to } 4.38) \\
\text { NAHS } 3.85 \text { ( } 2.91 \text { to } 4.78) \\
\text { VAS } 2.94(2.19 \text { to } 3.68) \\
\text { Flexion ROM }-2.07(-2.64 \text { to }-1.50) \\
\text { Extension ROM }-0.15(-0.47 \text { to } 0.17) \\
\text { Abduction ROM }-0.78(-1.15 \text { to }-0.41) \\
\text { Adduction ROM } 0.00(-0.32 \text { to } 0.32) \\
\text { ER in flexion ROM }-0.09(-0.41 \text { to } 0.23) \\
\text { ER in extension ROM }-0.88(-1.26 \text { to }-0.50) \\
\text { IR in flexion ROM } 4.27(3.24 \text { to } 5.29) \\
\text { IR in extension ROM }-0.16(-0.48 \text { to } 0.16)\end{array}$ \\
\hline $\begin{array}{l}\text { Guenther, et al } \\
2017^{35}\end{array}$ & $\begin{array}{l}\text { A pre-operative exercise intervention } \\
\text { can be safely delivered to people } \\
\text { withfemoroacetabular impingement } \\
\text { and improve clinical and biomechanical } \\
\text { outcomes }\end{array}$ & $\begin{array}{l}\text { HOOS Symptoms } 56.1(13.2) \\
\text { HOOS-Pain } 64.1(12.3) \\
\text { HOOS-ADL } 73.0(14.4) \\
\text { HOOS-Sport } 51.7(12.2) \\
\text { HOOS-QOL } 35.3(17.2) \\
\text { Abduction strength } 1.53(0.35) \\
\text { Adduction strength } 1.40(0.38) \\
\text { Extension strength } 1.81(0.46) \\
\text { Flexion strength } 1.89(0.45) \\
\text { ER strength } 0.75(0.23) \\
\text { IR strength } 0.76(0.36) \\
\text { Timed stair climb test 2.96 (0.66) }\end{array}$ & $\begin{array}{l}\text { HOOS Symptoms } 63.9(14.6) \\
\text { HOOS-Pain } 72.5(12.3) \\
\text { HOOS-ADL } 83.4(11.0) \\
\text { HOOS-Sport } 63.4(14.0) \\
\text { HOOS-QOL } 42.8(22.0) \\
\text { Abduction strength } 1.67(0.34) \\
\text { Adduction strength } 1.53(0.39) \\
\text { Extension strength } 1.93(0.50) \\
\text { Flexion strength } 2.04(0.43) \\
\text { ER strength } 0.77(0.18) \\
\text { IR strength } 0.89(0.36) \\
\text { Timed stair climb test } 2.61(0.46)\end{array}$ & $\begin{array}{l}\text { HOOS Symptoms } \\
\text { HOOS-Pain } \\
\text { HOOS-ADL } \\
\text { HOOS-Sport } \\
\text { HOOS-QOL } \\
\text { Abduction strength } 0.39(-0.07 \text { to } 0.84) \\
\text { Adduction strength } 0.32(-0.13 \text { to } 0.77) \\
\text { Extension strength } 0.24(-0.21 \text { to } 0.68) \\
\text { Flexion strength } 0.33(-0.12 \text { to } 0.78) \\
\text { ER strength } 0.09 \text { ( }-0.35 \text { to } 0.53) \\
\text { IR strength0.35 (-0.10 to } 0.80) \\
\text { Timed stair climb test } 0.57(0.10 \text { to } 1.05)\end{array}$ \\
\hline $\begin{array}{l}\text { Hunt, et al } \\
2012^{32}\end{array}$ & $\begin{array}{l}\text { Clinical outcomes analysis of } \\
\text { conservative and surgical treatment } \\
\text { of patients with clinical indications } \\
\text { of pre-arthritic, intra-articular hip } \\
\text { disorders }\end{array}$ & $\begin{array}{l}\text { HHS } 61.3 \pm 13 \\
\text { WOMAC } 29.2 \pm 16 \\
\text { NAHS } 63.2 \pm 14\end{array}$ & $\begin{array}{l}\text { HHS } 78.9 \pm 14 \\
\text { WOMAC } 13.5 \pm 14 \\
\text { NAHS } 81.6 \pm 12\end{array}$ & $\begin{array}{l}\text { HHS } 1.26 \text { (0.76 to } 1.77) \\
\text { WOMAC } 1.01 \text { (0.54 to } 1.47) \\
\text { NAHS } 1.36(0.84 \text { to } 1.89)\end{array}$ \\
\hline
\end{tabular}

ADL, activity of daily living; ER, external rotation; FU, follow-up time point; HAGOS, Copenhagen Hip and Groin Outcome Score; HHS, Harris Hip Score; HOOS, Hip Osteoarthritis and disability Outcome Score; IR, internal rotation; M, mean SD; MCS, emotional function subscale; NAHS, Non-Arthritic Hip Score; NPRS, Numeric Pain Rating Scale; NR, not reported; PA, physical activity; PCS, physical function subscale; PT, physiotherapy/physical therapy; QOL, quality of life; ROM, range of motion; SF-12, Short Form-12 Questionnaire; SMD, standardised mean difference; VAS, Visual Analogue Scale.

hip muscle strength gain was seen with a strengthening exercise programme of 3 months duration, ${ }^{40}$ and largest in hip adductor muscles. Greater hip adductor strength following hip arthroscopy is associated with better hip-related QOL, ${ }^{46}$ suggesting that it may be an important target. However, this was a pilot study, and the most effective type, dose and progression of exercise is unknown. The American College of Sports Medicine ${ }^{47}$ guidelines for exercise prescription contain information about the dosage, volume and progression of exercises that may be useful for clinicians and researchers when developing strength programmes for patients with hip pain. In studies measuring changes in functional task performance, had positive effects 3035 with movement retraining and functional exercise programmes. These programmes may improve patient self-efficacy as well as increase the capacity for load, thus enabling participation in more challenging activity. Larger, future studies including evaluating the potential of effect mediators and moderators may provide insight into the most effective physiotherapist-led interventions to improve physical impairments.

Returning to pre-injury sport and activity is important to young and middle-aged people with hip pain, and often the reason they seek surgical and/or non-surgical treatment. ${ }^{10} 48$ However, only two studies in this review had a specific return to sport/return to physical activity component within the physiotherapist-led intervention. ${ }^{33} 40$ Only $17 \%$ of people returned to optimal performance and full sports participation at $33 \pm 16$ months following hip arthroscopy. ${ }^{48}$ Given the importance of returning to sport in this active patient group and the disappointing rates of returning to optimal performance reported, ${ }^{48}$ future studies should incorporate key functional and sporting components. ${ }^{49}$ These could include: valid and consistent definitions of what comprises a successful return to sport and return to activity ${ }^{50}$; fully powered RCTs that include a specific, targeted return to sport programme throughout the duration of the intervention ${ }^{50}$ and inclusion of return to sport outcomes as a continuum. ${ }^{40}$ Until physiotherapist-led interventions include high-quality return to sport elements, outcomes are unlikely to improve beyond those reported by Ishoi et al. ${ }^{48}$

Transparency and reproducibility are critical when reporting the efficacy of clinical interventions. Guidelines such as the Consensus on Exercise Reporting Template ${ }^{51}$ and Template for Intervention Description and Replication checklist ${ }^{52}$ should be used in all trials reporting interventions to ensure adequate transparency and reproducibility. In addition, describing targeted strengthening interventions should use detailed procedures such as those described by Toigo and Boutellier. ${ }^{53}$ The documentation of adherence to exercise programmes is also critical. Such guidelines allow researchers to evaluate interventions and clinicians to reproduce efficacious interventions in clinical practice. Very few studies used these guidelines to report interventions in the current review. As such, it was not possible to pool findings to complete a meta-analysis, limiting the scope of the review. We recommend that future studies report physiotherapist-led interventions using guidelines such as those described above to maximise transparency and utility of study findings by researchers and clinicians alike.

This review contains several limitations that should be acknowledged. First, the methodological quality of the studies was variable, with only 4/14 (29\%) studies considered to have a low risk of bias. In the studies with a higher risk of bias, inflated effect sizes are possible, raising questions about the strength of the findings of these studies. Second, most of the included RCTs were pilot studies and as such were underpowered to detect statistically significant differences between groups. In addition, as there were no fully powered studies comparing physiotherapist-led interventions with sham interventions, adequately powered studies that undertake a head-to-head comparison of physiotherapist-led interventions are required to determine the optimal management strategies for hip pain in young and middleaged adults. Furthermore, the terminology used to describe hip 
Summary box

What is already known?

- Hip-related pain is common in young, active adults.

- Non-surgical treatments such as physiotherapist-led treatments should be first-line treatment for musculoskeletal conditions including hip-related pain, but effectiveness of these treatments is unclear.

What are the new findings?

- There is a paucity of literature in this field.

- Physiotherapist-led interventions improve function and strength.

- Effects of physiotherapist-led interventions on pain and quality of life are uncertain.

- Targeted strengthening exercise programmes and at least 3-month duration might have the best effect.

- Hip arthroscopy surgery had a small positive benefit compared with a physiotherapist-led intervention at 8-12 months.

- At 24 months, there was limited evidence suggesting no difference between groups.

disorders is not clear, and the populations that were included in this review may be heterogenous. The recent Zurich consensus statement on hip-related pain has provided some guidance in classifying hip disorders as FAI syndrome, acetabular dysplasia and 'other'. ${ }^{9}$ At present, there are not enough studies published to be able to analyse data separately for each of these three classifications. However, as the field evolves, this may be an approach that is appropriate for future reviews. As with all reviews of intervention studies, publication bias may have existed where studies with negative findings were not published. We also excluded studies not written in English, which may have led to inclusion bias. Finally, the PROMs and physical impairmentbased outcome measures used in the studies were inconsistent, which limited the pooling of data. A recent consensus ${ }^{54}$ determined that the HAGOS and IHOT were the most appropriate PROM for use in young and middle-aged people with hip pain, and future studies using these measures may make stratification and pooling of data based on these measures in future reviews possible. Furthermore, it is not yet clear what is considered an acceptable level of improvement in a patient's condition. We compared the findings of our review to previously published PASS and MIC scores, to provide some context to clinical relevance of the effects reported. We acknowledge that the previously published PASS and MIC scores were determined in studies of posthip arthroscopy and posthip arthroplasty patients. It is not known what constitutes a PASS and MIC in non-surgical cohorts of people with hip-related pain. The inclusion of PASS questions at specific time points in future studies may help determine whether patients are gaining acceptable improvement when undergoing physiotherapist-led interventions.

\section{CONCLUSION}

There were no full-scale RCTs comparing physiotherapist-led interventions with other non-surgical treatments or sham treatments. The risk of bias in included studies, as well as limitations in included study methodology should be considered in the interpretation of the results of this systematic review. Physiotherapist-led interventions may improve pain and function in young and middle-aged adults experiencing hip pain, including those with FAI syndrome. There was limited evidence of larger effects for interventions that included targeted strengthening exercise programmes and were of 3 months duration. Hip arthroscopy surgery had a weak positive effect compared with a physiotherapist-led intervention at 8-12 months. Future full-scale RCTs undertaking a head-to-head comparison of physiotherapist-led interventions for hip pain are required.

Correction notice This article has been corrected since it published Online First. An ORCID ID has been added for author Steven Chang.

Twitter Joanne L Kemp @JoanneLKemp, Andrea B Mosler @AndreaBMosler, Mark J Scholes@MarkScholes85 and Adam I Semciw @ASemciw

Contributors JK, AMB, KMC developed the research question and concept. JK and SC performed the search. JK, HH, MB, MJS performed risk of bias assessment. JK and AMB performed data extraction. JK and AIS performed data analyses. All authors contributed to drafting of manuscript.

Funding JK is supported by an NHMRC (Australia) ECF 1119971.

Competing interests None declared.

Patient consent for publication Not required.

Ethics approval Institutional ethical approval was not required as no data were collected on humans or animals in this review.

Provenance and peer review Not commissioned; externally peer reviewed.

Data availability statement Data extracted are shared at Figshare (https:// figshare.com/s/d18bcb066f1de48861cf).

Open access This is an open access article distributed in accordance with the Creative Commons Attribution Non Commercial (CC BY-NC 4.0) license, which permits others to distribute, remix, adapt, build upon this work non-commercially, and license their derivative works on different terms, provided the original work is properly cited, appropriate credit is given, any changes made indicated, and the use is non-commercial. See: http://creativecommons.org/licenses/by-nc/4.0/.

\section{ORCID iDs}

Joanne L Kemp http://orcid.org/0000-0002-9234-1923

Andrea B Mosler http://orcid.org/0000-0001-7353-2583

Harvi Hart http://orcid.org/0000-0002-5802-510X

Steven Chang http://orcid.org/0000-0002-3193-7969

Mark J Scholes http://orcid.org/0000-0001-9216-1597

Adam I Semciw http://orcid.org/0000-0001-5399-7463

Kay M Crossley http://orcid.org/0000-0001-5892-129X

\section{REFERENCES}

1 Vos T, Flaxman AD, Naghavi M, et al. Years lived with disability (YLDs) for 1160 sequelae of 289 diseases and injuries 1990-2010: a systematic analysis for the global burden of disease study 2010. Lancet 2012;380:2163-96.

2 Werner J, Hägglund $M$, Waldén $M$, et al. UEFA injury study: a prospective study of hip and groin injuries in professional football over seven consecutive seasons. Br J Sports Med 2009;43:1036-40.

3 Werner J, Hägglund M, Ekstrand J, et al. Hip and groin time-loss injuries decreased slightly but injury burden remained constant in men's professional football: the 15year prospective UEFA elite Club injury study. Br J Sports Med 2019;53:539-546.

4 Mosler $A B$, Weir $A$, Eirale $C$, et al. Epidemiology of time loss groin injuries in a men's professional football League: a 2-year prospective study of 17 clubs and 606 players. Br J Sports Med 2018;52:292-7.

5 Kierkegaard S, Langeskov-Christensen M, Lund B, et al. Pain, activities of daily living and sport function at different time points after hip arthroscopy in patients with femoroacetabular impingement: a systematic review with meta-analysis. Br J Sports Med 2017:51:572-9.

6 Thorborg K, Kraemer O, Madsen AD, et al. Patient-Reported outcomes within the first year after hip arthroscopy and rehabilitation for femoroacetabular impingement and/ or Labral injury: the difference between getting better and getting back to normal. Am J Sports Med 2018:363546518786971.

7 Griffin DR, Dickenson EJ, Wall PDH, et al. Hip arthroscopy versus best conservative care for the treatment of femoroacetabular impingement syndrome (UK fashion): a multicentre randomised controlled trial. Lancet 2018;391:2225-35.

8 Mansell NS, Rhon DI, Meyer J, et al. Arthroscopic surgery or physical therapy for patients with femoroacetabular impingement syndrome: a randomized controlled trial with 2-year follow-up. Am J Sports Med 2018;46:1306-14.

9 Reiman MP, Agricola R, Kemp JL, et al. Consensus recommendations on the classification, definition and diagnostic criteria of hip-related pain in young and middle-aged active adults from the International Hip-related pain research network, Zurich 2018. British Journal of Sports Medicine 2019. 
10 Griffin DR, Dickenson EJ, O'Donnell J, et al. The Warwick agreement on femoroacetabular impingement syndrome (FAl syndrome): an international consensus statement. Br J Sports Med 2016;50:1169-76.

11 Mascarenhas VV, Rego P, Dantas P, et al. Imaging prevalence of femoroacetabular impingement in symptomatic patients, athletes, and asymptomatic individuals: a systematic review. Eur J Radiol 2016;85:73-95.

12 Ganz R, Parvizi J, Beck M, et al. Femoroacetabular impingement: a cause for osteoarthritis of the hip. Clin Orthop Relat Res 2003;417:112-20.

13 Agricola R, Waarsing JH, Arden NK, et al. Cam impingement of the hip: a risk factor for hip osteoarthritis. Nat Rev Rheumatol 2013;9:630-4.

14 Kemp JL, Makdissi M, Schache AG, et al. Hip chondropathy at arthroscopy: prevalence and relationship to labral pathology, femoroacetabular impingement and patientreported outcomes. Br J Sports Med 2014;48:1102-7.

15 McAlindon TE, Bannuru RR, Sullivan MC, et al. OARSI guidelines for the non-surgical management of knee osteoarthritis. Osteoarthritis Cartilage 2014;22:363-88.

16 Fernandes L, Hagen KB, Bijlsma JWJ, et al. EULAR recommendations for the nonpharmacological core management of hip and knee osteoarthritis. Ann Rheum Dis 2013;72:1125-35

17 Koes BW, van Tulder M, Lin C-WC, et al. An updated overview of clinical guidelines for the management of non-specific low back pain in primary care. Eur Spine $J$ 2010;19:2075-94

18 Kemp JL, King MG, Barton C, et al. Is exercise therapy for femoroacetabular impingement in or out of fashion? we need to talk about current best practice for the non-surgical management of FAI syndrome. Br J Sports Med 2019;53:1205

19 Portney L, Watkins M. Foundations of Clinical Research - Applications to Clinical Practice. 3rd ed. Upper Saddle River, New Jersey: Pearson Education, 2009.

20 van Tulder M, Furlan A, Bombardier C, et al. Updated method guidelines for systematic reviews in the Cochrane collaboration back review group. Spine 2003;28:1290-9.

21 Wallis JA, Webster KE, Levinger $P$, et al. What proportion of people with hip and knee osteoarthritis meet physical activity guidelines? A systematic review and metaanalysis. Osteoarthritis Cartilage 2013;21:1648-59.

22 Paulsen $A$, Roos EM, Pedersen AB, et al. Minimal clinically important improvement (MCII) and patient-acceptable symptom state (pass) in total hip arthroplasty (THA) patients 1 year postoperatively. Acta Orthop 2014;85:39-48.

23 Maxwell S, Pergaminelis N, Renouf J, et al. Identification of a patient acceptable symptomatic state score for the International hip outcome tool in people undergoing hip arthroscopy. Arthroscopy 2018;34:3024-9.

24 Chahal J, Thiel GSV, Mather RC, et al. The minimal clinical important difference (MCID) and patient acceptable symptomatic state (pass) for the modified Harris hip score and hip outcome score among patients undergoing surgical treatment for femoroacetabular impingement. Orthop J Sports Med 2014;2:2325967114S0010.

25 Kemp JL, Collins NJ, Roos EM, et al. Psychometric properties of patient-reported outcome measures for hip arthroscopic surgery. Am J Sports Med 2013;41:2065-73.

26 Wan X, Wang W, Liu J, et al. Estimating the sample mean and standard deviation from the sample size, median, range and/or interquartile range. BMC Med Res Methodol 2014;14:135.

27 Dang TM, Peters MJ, Hickey B, et al. Efficacy of flattening-filter-free beam in stereotactic body radiation therapy planning and treatment: a systematic review with meta-analysis. J Med Imaging Radiat Oncol 2017;61:379-87.

28 Cohen J. Statistical power analysis for the behavioral sciences. 2nd ed. Hillsdale, N.J: Lawrence Erlbaum Associates, 1988.

29 Landis JR, Koch GG. Agreement methods for categorical data. Biometrics 1977:33:159-74.

30 Coppack RJ, Bilzon JL, Wills AK, et al. Physical and functional outcomes following multidisciplinary residential rehabilitation for prearthritic hip pain among young active UK military personnel. BMJ Open Sport Exerc Med 2016;2:e000107.

31 Emara K, Samir W, Motasem ELH, et al. Conservative treatment for mild femoroacetabular impingement. Journal of Orthopaedic Surgery 2011;19:41-5.

32 Hunt D, Prather $\mathrm{H}$, Harris-Hayes $\mathrm{M}$, et al. Clinical outcomes analysis of conservative and surgical treatment of patients with clinical indications of Prearthritic, intraarticular hip disorders. PM\&R 2012;4:479-87.

33 Bennell KL, Spiers L, Takla A, et al. Efficacy of adding a physiotherapy rehabilitation programme to arthroscopic management of femoroacetabular impingement syndrome: a randomised controlled trial (fair). BMJ Open 2017;7:e014658.

34 Grant LF, Cooper DJ, Conroy JL. The HAPI 'Hip Arthroscopy Pre-habilitation Intervention' study: does pre-habilitation affect outcomes in patients undergoing hip arthroscopy for femoro-acetabular impingement? J Hip Preserv Surg 2017:50:hnw046-92.

35 Guenther JR, Cochrane CK, Crossley KM, et al. A pre-operative exercise intervention can be safely delivered to people with femoroacetabular impingement and improve clinical and biomechanical outcomes. Physiotherapy Canada 2017;69:204-11.

36 Kemp J, Moore K, Fransen M, et al. A pilot randomised clinical trial of physiotherapy (manual therapy, exercise, and education) for early-onset hip osteoarthritis post-hip arthroscopy. Pilot and Feasibility Studies 2018;4.

37 Smeatham A, Powell R, Moore S, et al. Does treatment by a specialist physiotherapist change pain and function in young adults with symptoms from femoroacetabular impingement? A pilot project for a randomised controlled trial. Physiotherapy 2017:103:201-7

38 Wright AA, Hegedus EJ, Taylor JB, et al. Non-Operative management of femoroacetabular impingement: a prospective, randomized controlled clinical trial pilot study. J Sci Med Sport 2016;19:716-21.

39 Harris-Hayes M, Czuppon S, Van Dillen LR, et al. Movement-Pattern training to improve function in people with chronic hip joint pain: a feasibility randomized clinica trial. J Orthop Sports Phys Ther 2016;46:452-61.

40 Kemp JL, Coburn SL, Jones DM, et al. The physiotherapy for femoroacetabular impingement rehabilitation study (physioFIRST): a pilot randomized controlled trial. J Orthop Sports Phys Ther 2018;48:307-15.

41 Palmer AJR, Ayyar Gupta V, Fernquest S, et al. Arthroscopic hip surgery compared with physiotherapy and activity modification for the treatment of symptomatic femoroacetabular impingement: multicentre randomised controlled trial. BMJ 2019;9:1185

42 Kemp JL, Risberg MA, Mosler A, et al. Physiotherapist-led treatment for young to middle-aged active adults with hip-related pain: consensus recommendations from the International Hip-related pain research network, Zurich 2018. Br J Sports Med 2020;54:504-11.

43 Risberg MA, Ageberg E, Nilstad A, et al. Arthroscopic surgical procedures versus sham surgery for patients with femoroacetabular impingement and/or Labral tears: study protocol for a randomized controlled trial (HIPARTI) and a prospective cohort study (HARP). J Orthop Sports Phys Ther 2018;48:325-35.

44 Beumer L, Wong J, Warden SJ, et al. Effects of exercise and manual therapy on pain associated with hip osteoarthritis: a systematic review and meta-analysis. $\mathrm{Br} J$ Sports Med 2016;50:458-63.

45 Abbott JH, Wilson R, Pinto D, et al. Incremental clinical effectiveness and cost effectiveness of providing supervised physiotherapy in addition to usual medica care in patients with osteoarthritis of the hip or knee: 2-year results of the moa randomised controlled trial. Osteoarthritis and Cartilage 2019;27:424-34.

46 Kemp JL, Makdissi M, Schache AG, et al. Is quality of life following hip arthroscopy in patients with chondrolabral pathology associated with impairments in hip strength or range of motion? Knee Surgery, Sports Traumatology. Arthroscopy 2015:1-7.

$47 \mathrm{ACOS}$ M. ACSM's guidelines for exercise testing and prescription. 10th ed. Philadelphia, PA: Wolters Kluwer/Lippincott Williams \& Wilkins, 2017.

48 Ishoi L, Thorborg K, Kraemer O, et al. Return to sport and performance after hip arthroscopy for femoroacetabular impingement in 18- to 30-year-old athletes: a cross sectional cohort study of 189 athletes. Am J Sports Med 2018:363546518789070.

49 Mosler AB, Kemp J, King M, et al. Standardised measurement of physical capacity in young and middle-aged active adults with hip-related pain: recommendations from the first international Hip-related pain research network (IHiPRN) meeting, Zurich, 2018. Br J Sports Med 2019:bjsports-2019-101457.

50 Ardern CL, Glasgow P, Schneiders A, et al. 2016 consensus statement on return to sport from the first world Congress in sports physical therapy, Bern. Br J Sports Med 2016:50:853-64.

51 Slade SC, Dionne CE, Underwood M, et al. Consensus on exercise reporting template (CERT): explanation and elaboration statement. Br J Sports Med 2016;50:1428-37.

52 Hoffmann TC, Glasziou PP, Boutron I, et al. Better reporting of interventions: template for intervention description and replication (TIDieR) checklist and guide. BMJ 2014;348:g1687.

53 Toigo M, Boutellier U. New fundamental resistance exercise determinants of molecular and cellular muscle adaptations. Eur J App/ Physiol 2006;97:643-63.

54 Impellizzeri FM, Jones DM, Griffin D, et al. Patient-Reported outcome measures for hip-related pain: a review of the available evidence and a consensus statement from the International Hip-related pain research network, Zurich 2018. Br J Sports Med 2020:bjsports-2019-101456. 